\title{
The effects of high glucose on tendon-derived stem cells: implications of the pathogenesis of diabetic tendon disorders
}

\author{
Yu-Cheng Lin ${ }^{1, *}$, Ying-Juan Li ${ }^{2, *}$, Yun-Feng Rui ${ }^{1,3,4}$, Guang-Chun Dai ${ }^{1}$, Liu Shi, ${ }^{1,5,6}$, \\ Hong-Liang $\mathrm{Xu}^{3}$, Ming $\mathrm{Ni}^{7}$, Song $\mathrm{ZhaO}^{1}$, Hui Chen ${ }^{1}$, Chen Wang ${ }^{1}$, Gang $\mathrm{Li}^{5,6}$ and Gao- \\ Jun Teng ${ }^{8}$ \\ ${ }^{1}$ Department of Orthopaedics, Zhongda Hospital, School of Medicine, Southeast University, Nanjing, Jiangsu, China \\ 2 Department of Geriatrics, Zhongda Hospital, School of Medicine, Southeast University, Nanjing, China \\ ${ }^{3}$ Department of Orthopaedics, Xishan People's Hospital, Wuxi, Jiangsu, China \\ ${ }^{4}$ China Orthopedic Regenerative Medicine Group, China \\ ${ }^{5}$ Department of Orthopaedics and Traumatology, Faculty of Medicine, The Chinese University of Hong Kong, Hong Kong, \\ SAR, China \\ ${ }^{6}$ Program of Stem Cell and Regeneration, School of Biomedical Science, and Li Ka Shing Institute of Health Sciences, Faculty \\ of Medicine, The Chinese University of Hong Kong, Hong Kong, SAR, China \\ 7 Department of Orthopaedics, The General Hospital of Chinese People's Liberation Army, Beijing, China \\ ${ }^{8}$ Department of Radiology, Jiangsu Key Laboratory of Molecular and Functional Imaging, Zhongda Hospital, School of \\ Medicine, Southeast University, Nanjing, Jiangsu, China \\ * These authors have contributted equally to this work \\ Correspondence to: Yun-Feng Rui, email: ruiyunfeng@126.com
}

Gao-Jun Teng, email: gjteng@vip.sina.com

Keywords: tendon-derived stem cells; high glucose; diabetic tendon disorders; pathogenesis; Pathology Section

Received: November 30, $2016 \quad$ Accepted: February 07, 2017

Published: February 16, 2017

\section{ABSTRACT}

Patients with diabetes are at great risk to suffer many musculoskeletal disorders, such as tendinopathy, tendon rupture and impaired tendon healing. However, the pathogenesis of these tendon disorders still remains unclear. In this study, we aimed to investigate the effects of high glucose on cell proliferation, cell apoptosis and tendon-related markers expression of tendon-derived stem cells (TDSCs) in vitro. These findings might provide new insights into the pathogenesis of diabetic tendon disorders. The cell proliferative ability and apoptosis rate of TDSCs in different groups were evaluated by MTT assay and Annexin V-FITC/PI staining assay. The mRNA expression of tendon-related markers (Scleraxis and Collagen I alpha 1 chain) were assessed by qRT-PCR. The protein expression of tendon-related markers (Tenomodulin and Collagen I) were measured by Western blotting. The proliferative ability of TDSCs treated with high glucose $(15 \mathrm{mM}$ and $25 \mathrm{mM})$ decreased significantly at day 1 , day 3 and day5. The cell apoptosis of TDSCs increased significantly when they were cultured with high glucose for $\mathbf{4 8 h}$ in vitro. The gene expression of Scleraxis and Collagen I alpha 1 chain in TDSCs decreased significantly when they were treated with high glucose for $24 \mathrm{~h}$ and $48 \mathrm{~h}$. The protein expression of Tenomodulin and Collagen $\mathrm{I}$ in TDSCs decreased significantly when they were treated with high glucose for $24 \mathrm{~h}$ and 48h. High glucose could inhibit cell proliferation, induce cell apoptosis and suppress the tendon-related markers expression of TDSCs in vitro. These findings might account for some pathological mechanisms underlying the pathogenesis of diabetic tendon disorders. 


\section{INTRODUCTION}

Patients with diabetes, both type 1 and type 2 are at greater risk to suffer many musculoskeletal disorders, such as tendinopathy, limited joint mobility, tendon ruptures, adhesive capsulitis and impaired tendon healing ability than non-diabetic patients [1-6]. Recently, a strong evidence has been reported that diabetes is associated with higher risk of tendinopathy [5]. The tendon seems to be particularly sensitive to impair with degenerative changes in about $40 \%$ of diabetic patients [3]. Diabetic patients have a greater risk of tendinopathy and/or traumatic rupture in musculoskeletal tissues because of the altered structural properties in tendon [7]. For the impaired Achilles tendons, patients with diabetes have higher proportion of postoperative infection and weaker tendon healing ability [6]. However, the underlying cellular and molecular mechanisms of the pathogenesis of diabetic tendon disorders are still unknown.

While tendons are supposed to be mainly comprised of tenocytes and collagens, recent studies have demonstrated that tendons from human, mice, rats, and rabbits also contain stem cell populations [8-11]. These stem cell populations isolated from tendon tissues were termed as tendon-derived stem cells (TDSCs). Like other adult stem cells, TDSCs have stem cell characteristics, including clonogenicity, self-renewing ability and the multi-differentiation potential [10]. TDSCs could promote tendon repair and regeneration, and might maintain tendon homeostasis $[12,13]$. The depletion of the stem cell pool and erroneous (non-tenogenic) differentiation of TDSCs might play an essential role in the pathogenesis of tendinopathy [14-16]. TDSCs might also be involved in the pathogenesis of diabetic tendon disorders [17].

A recent study showed that high plasma glucose levels might be a risk factor for rotator cuff tear [18].
Hyperglycemia produces a reduction in proteoglycans levels, which may contribute to the tendon pathology observed clinically in diabetes [19]. High glucose level alters the response of tendon cells to oxidative stress and high glucose increases the expression of MMP-9 and MMP-13 in tendon cells in vitro [20,21]. Nevertheless, the effects of high glucose concentration on TDSCs have not been investigated. We hypothesized that high glucose could impair cell proliferation, induce cell apoptosis and alter tendon-related markers expression of TDSCs, which might be a potential cellular mechanism of the pathogenesis of diabetic tendon disorders. In this study, we aims to investigate the effects of different glucose concentrations $(5.5 \mathrm{mM}, 15 \mathrm{mM}$, and $25 \mathrm{mM})$ on the proliferation, apoptosis and tendon-related markers expression of rat TDSCs in vitro. All these findings might provide some new insights into the pathogenesis of diabetic tendon disorders.

\section{RESULTS}

\section{Inhibition of cell proliferation}

Cells were treated with different concentrations of glucose medium for 1 day, 3 days and 5 days, and viable cells were monitored by MTT assay. Cell morphology of TDSCs was slightly changed when they were treated with high glucose concentration for $24 \mathrm{~h}$. Treatment of TDSCs with high glucose $(15 \mathrm{mM}$ and $25 \mathrm{mM})$ decreased cell proliferation at day1, day3 and day5 (Figure 1). The results showed the significant differences between high glucose groups (15 and $25 \mathrm{mM}$ ) and normal glucose group (5.5mM), which implied that high glucose could inhibit TDSCs proliferation in vitro.

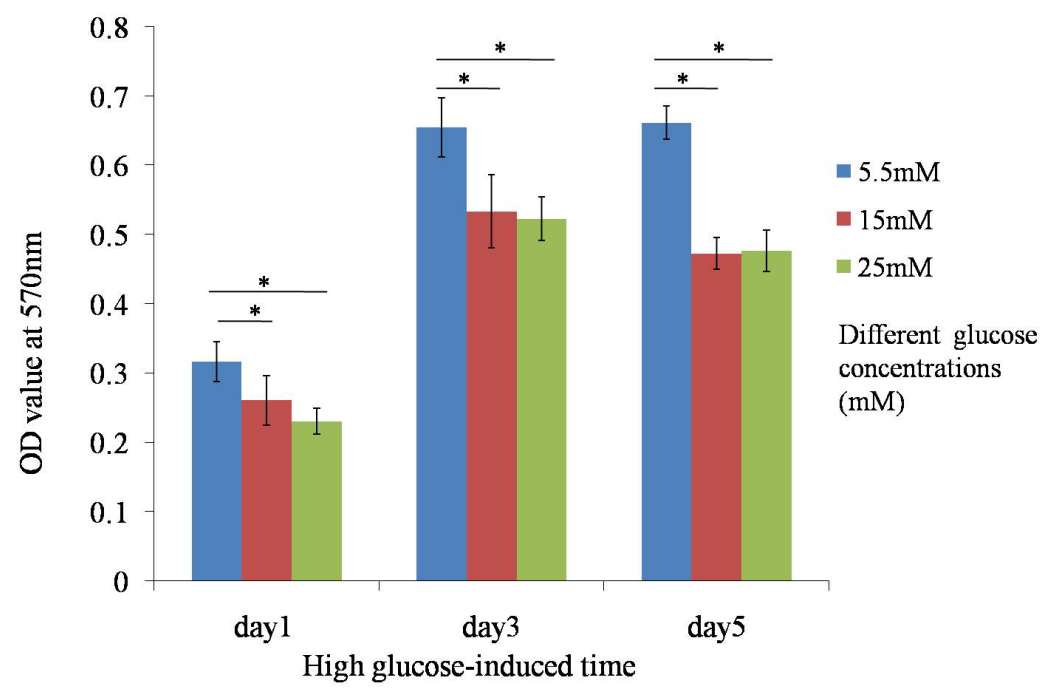

Figure 1: MTT assay. Treatment of TDSCs with high glucose (15mM and 25mM) decreased cell proliferation at day1, day3 and day5. $* P \leq 0.05$. 


\section{Induction of cell apoptosis}

Viable, early and late apoptotic or necrotic cells can be identified by flow cytometry analysis using dual staining with annexin V/PI dyes. We treated TDSCs with different glucose concentrations $(5.5 \mathrm{mM}, 15 \mathrm{mM}$, and $25 \mathrm{mM}$ ) for 24 hours and 48 hours, and measured the apoptosis rate. Flow cytometry analysis showed that there was no statistical difference between high glucose groups (15 and $25 \mathrm{mM}$ ) and normal glucose group $(5.5 \mathrm{mM})$ after 24 hours culture, however, significant differences were observed between high glucose groups (both 15 and $25 \mathrm{mM})$ and normal glucose group $(5.5 \mathrm{mM})$ at 48 hours (Figure 2). Overall, high glucose could induce cell apoptosis when TDSCs were cultured with high glucose for 48 hours in vitro.

\section{Suppression of the key tendon-related markers expression of TDSCs}

The results of the qRT-PCR assay showed that the mRNA expression of Scx and Collal were downregulated when they were treated with 15 and $25 \mathrm{mM}$ glucose at 24 hours and 48 hours, compared with those in normal glucose group $(5.5 \mathrm{mM})$. The results suggested that high glucose could down-regulate the mRNA expression of tendon-related markers of TDSCs after 24 hours and 48 hours culture. (Figures 3, 4).

The protein expression of Tnmd was lower in treatment with high glucose concentrations $(15 \mathrm{mM}$ and $25 \mathrm{mM}$ ) at 24 hours and 48 hours, compared with treatment with $5.5 \mathrm{mM}$ glucose concentration. The expression of Col-1 was similar to Tnmd. The protein expression of Col1 in TDSCs was decreased after the high glucose treatment ( $15 \mathrm{mM}$ and $25 \mathrm{mM})$ for 24 hours and 48 hours compared with that in $5.5 \mathrm{mM}$ glucose group. (Figures $5,6,7$ ).
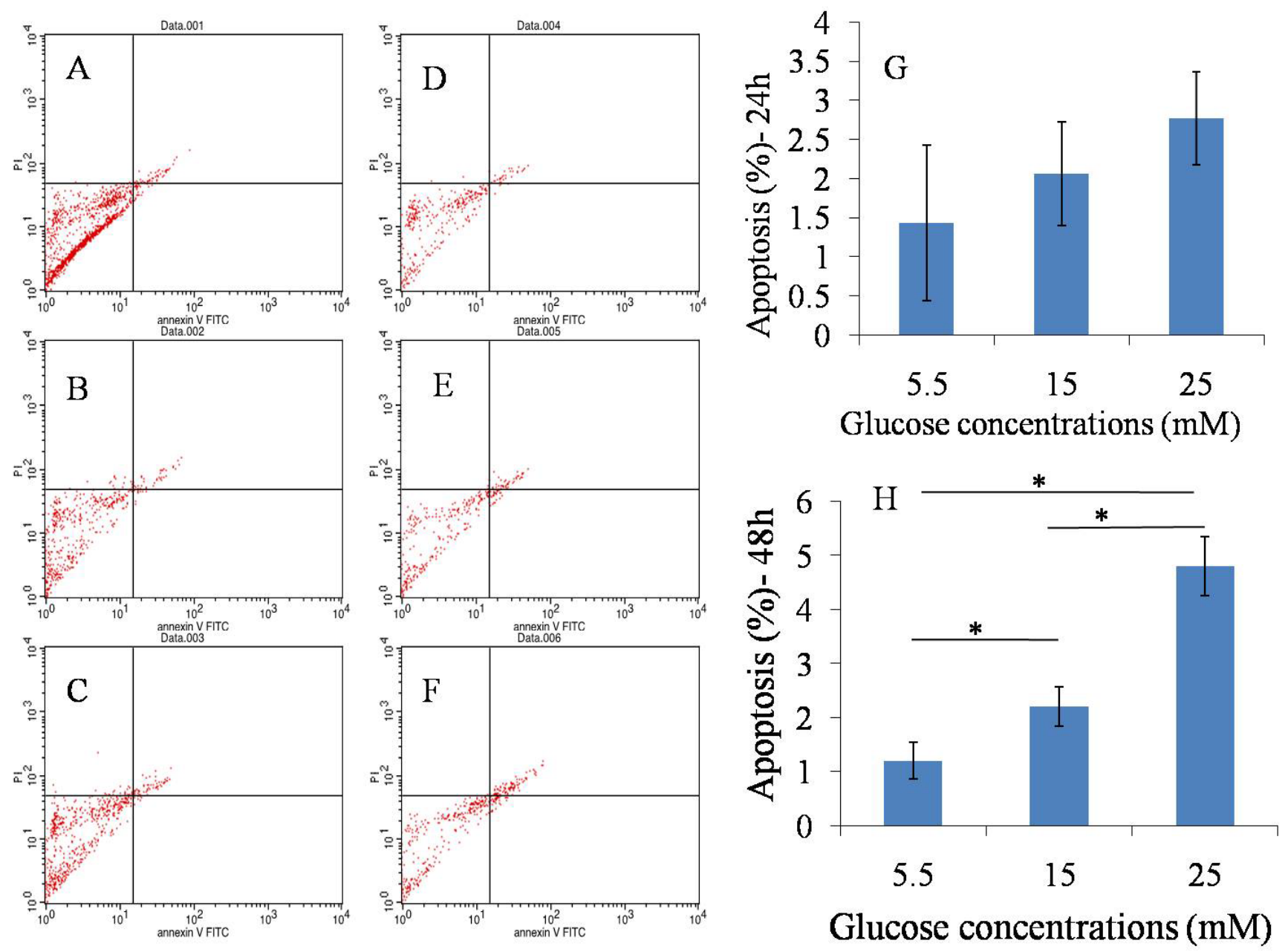

Figure 2: Apoptosis assay. A., B., C.. $24 \mathrm{~h}$ after $5.5 \mathrm{mM}, 15 \mathrm{mM}, 25 \mathrm{mM}$ glucose induction separately; D., E., F.. $48 \mathrm{~h}$ after $5.5 \mathrm{mM}$, $15 \mathrm{mM}, 25 \mathrm{mM}$ glucose induction separately; G. Statistical results in $24 \mathrm{~h}$; H. Statistical results in $48 \mathrm{~h}$. There was no statistical difference between high glucose groups $(15$ and $25 \mathrm{mM})$ and normal glucose group $(5.5 \mathrm{mM})$ after 24 hours culture, however, significant differences were observed between high glucose groups and normal glucose group at 48 hours. $* P \leq 0.05$. 


\section{DISCUSSION}

In this study, we found that high glucose could inhibit cell proliferation and induce cell apoptosis of TDSCs in vitro. The tenogenic differentiation ability of TDSCs was decreased in the initial stage (incubation time for $24 \mathrm{~h}$ and $48 \mathrm{~h}$ ), in vitro. All these findings proved our hypothesis and accounted for the potential pathogenesis of diabetic tendon disorders including diabetic tendinopathy, tendon rupture and impaired tendon healing (Figure 8).

Our experiment was designed to simulate the normal blood glucose environment in non-diabetics and the hyperglycemic environment in diabetics in vitro. In healthy individuals, blood glucose is tightly sustained from $4 \mathrm{mM}$ to $7 \mathrm{mM}$. In diabetics, levels can rise appreciably higher. Serious diabetic complications can arise when levels exceed $13 \mathrm{mM}$, and concentrations of up to $33 \mathrm{mM}$ are often dangerous. Thomas et al. demonstrated that the glucose concentration in subcutaneous tissue closely resembled that in plasma [22]. As we know, healthy tendon does not have intrinsic blood supply and is separated with the surrounding muscle by tendon sheath. Our previous study also showed the cellularity and vascularity were insignificant in the healthy patellar tendons, however, hypercellularity and hypervascularity were observed in patellar tendinopathy samples [23]. The normally hypovascularized tendon tissue becomes hypervascularized during the procedure of degenerative disease [24]. The Achilles tendons in diabetic rats showed vascular feedbacks uncommon to healthy tendons, such as the increase in vascular density and vascular hyperplasia [25]. Our unpublished data also showed vascularization
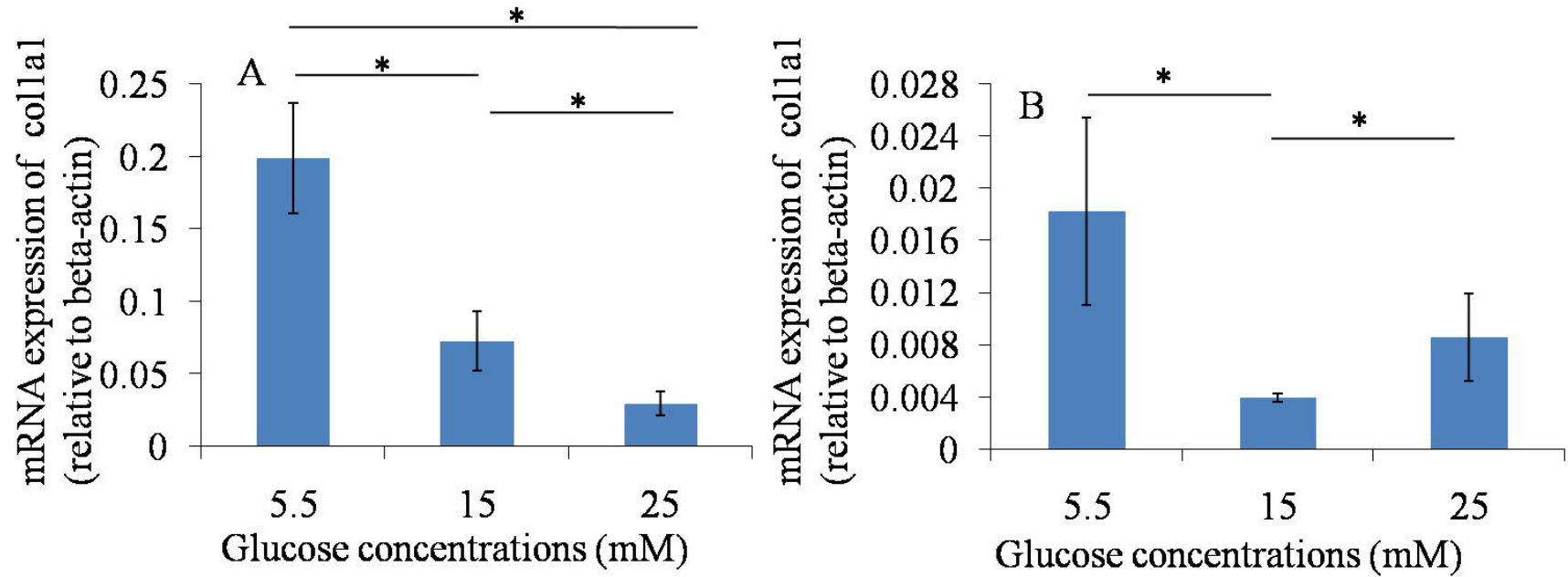

Figure 3: qRT-PCR assay----Col1a1. A. 24h after glucose induction; B. 48h after glucose induction; The mRNA expression of Colla1 was down-regulated when TDSCs were treated with high glucose $(15 \mathrm{mM}$ and $25 \mathrm{mM})$ at 24 hours and 48 hours, compared with that in normal glucose group $(5.5 \mathrm{mM}) . * P \leq 0.05$.
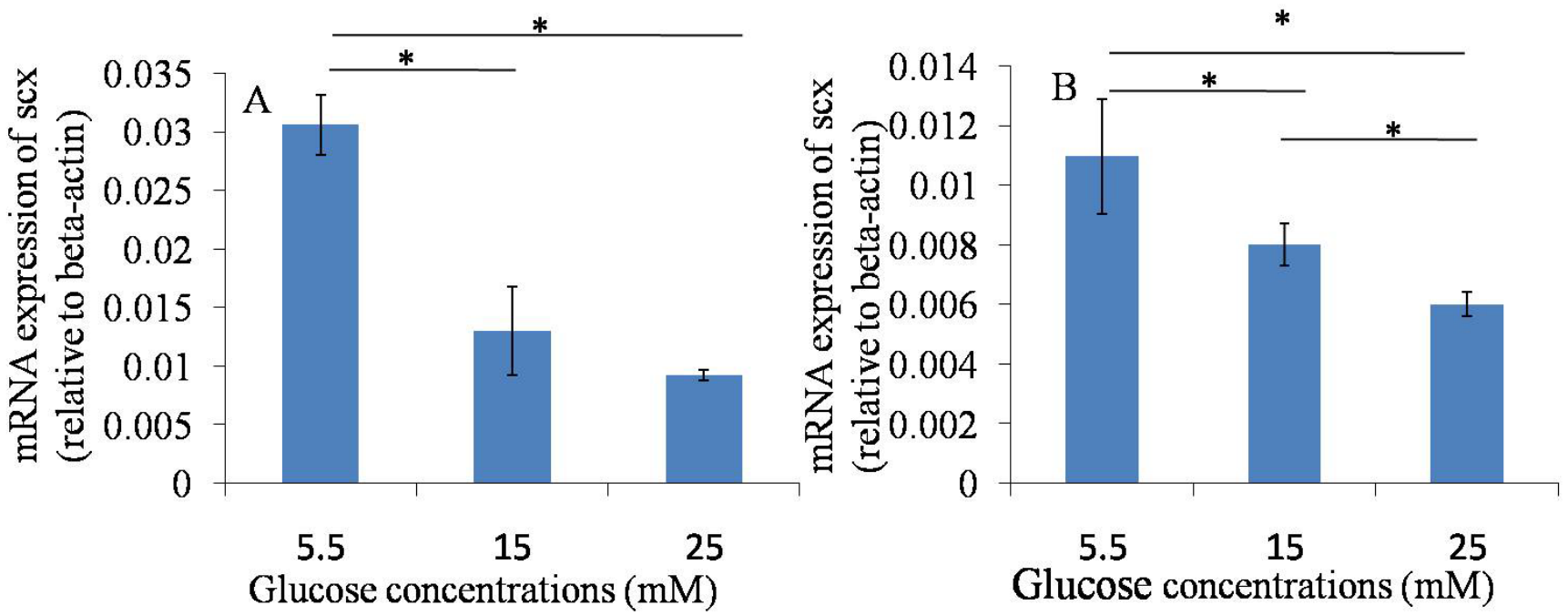

Figure 4: qRT-PCR assay----Scx. A. 24h after glucose induction; B. 48h after glucose induction; The mRNA expression of Scx was down-regulated when TDSCs were treated with high glucose $(15 \mathrm{mM}$ and $25 \mathrm{mM})$ at 24 hours and 48 hours, compared with that in normal glucose group $(5.5 \mathrm{mM}) .{ }^{*} P \leq 0.05$. 
in tendons of diabetic animal model. Furthermore, there has been no report on the glucose concentration in tendon tissue in the normal population or in diabetic patients. Therefore, the glucose concentrations $(5.5 \mathrm{mM}, 15 \mathrm{mM}$ and $25 \mathrm{mM}$ ) were used to simulate the normal and diabetic environments according to Thomas's research.

High blood glucose is the key pathogenic inducer that leads to diabetic complications including musculoskeletal disorders. The adverse effects of high glucose on various mesenchymal stem cells have been known for a long time. Increasing evidence indicates that high glucose inhibits the proliferation, migration and angiogenic ability of bone marrow-derived progenitor cells in vitro, and alters the regenerative potential of mesenchymal stem cells [26, 27]. Moreover, researchers demonstrate that high glucose inhibits the proliferation and mineralization of periodontal ligament stem cells in vitro [28]. Glucose overdose is a potential pathogenic factor of cytotoxic, genotoxic, and apoptotic effects on tumors cells [29].

This is the first study, to our knowledge, to discuss the effects of different glucose levels on TDSCs in vitro. In the present study, we demonstrated a decrease in the proliferative capacity of TDSCs in high glucose concentration level. Our results are similar to the previous reports mentioned above. We also found that TDSCs cultured in high glucose medium $(15 \mathrm{mM}, 25 \mathrm{mM})$ for $48 \mathrm{~h}$ led to a significant increase in apoptosis. Similar results were found in the neural stem cells followed by high glucose intervention in vitro [30]. After injury, TDSCs would proliferate and differentiate into tenocytes in normal tendon healing process [15]. The proliferative
Intervention time

Tnmd

COL-1

Actin

Glucose concentrations

$(\mathrm{mM})$
High glucose $24 \mathrm{~h}$
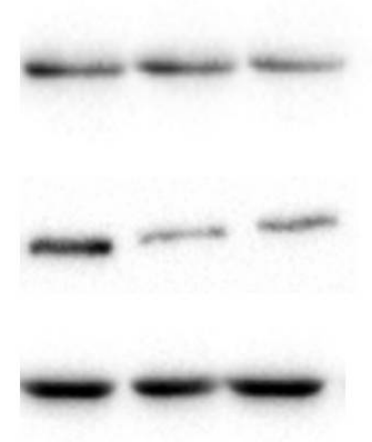

$5.5 \quad 15 \quad 25$

\section{High glucose $48 \mathrm{~h}$}
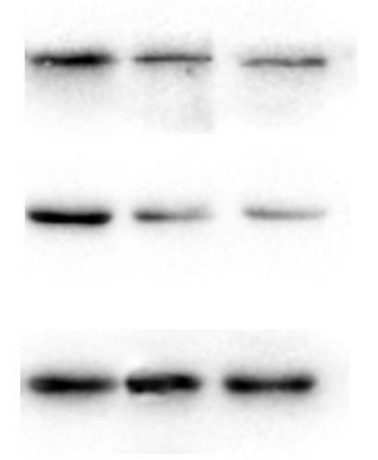

$5.5 \quad 15$

25

Figure 5: Western blotting assay. The expression of tendon-related proteins (Tnmd and Col-1).
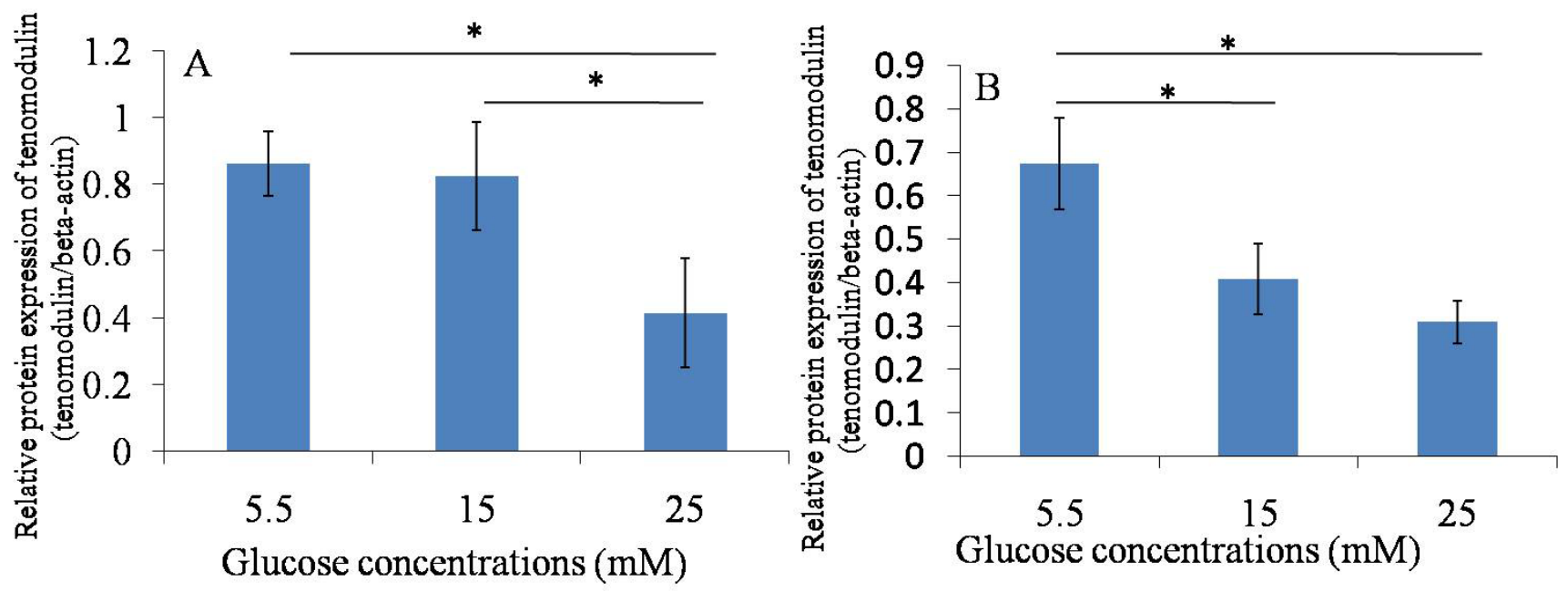

Figure 6: Western blotting ----Tnmd. A. 24h after glucose induction; B. 48h after glucose induction; The protein expression of Tnmd was decreased in treatment with high glucose concentrations $(15 \mathrm{mM}$ and $25 \mathrm{mM})$ at 24 hours and 48 hours, compared with treatment with $5.5 \mathrm{mM}$ glucose concentration. $* P \leq 0.05$. 
potential and viability of TDSCs play a vital role in maintaining the physiological function of tendon. The reduced proliferation ability of TDSCs, coupled with increased apoptosis might reduce the pool of TDSCs for tendon repair in diabetic patients.

There are some key factors playing important roles in tendon differentiation. Tnmd is a tendon-specific marker known to be important for TDSCs tenogenic differentiation [8]. Scx is also a marker of the tenocyte lineage. Scx itself is a transcription factor, which directly regulates expression of colla1 and colla2 [31].
Furthermore, Shukunami, C., et al. found that Tnmd was a marker of tendon formation and Scx positively regulated Tnmd expression in a tendon cell lineage-dependent manner [32]. Tendon extracellular matrix mainly containing collagen type I, shows a highly organized parallel structure around the tenocytes. The synthesis of collagen type I is crucial to maintain tendon structure, for collagen type I is the main ingredient of tendons [33]. Mohawk homeobox (MKX) has been demonstrated as a tendon specific transcription factor. Previous studies have shown that Scx is essential for the initiation of tendon
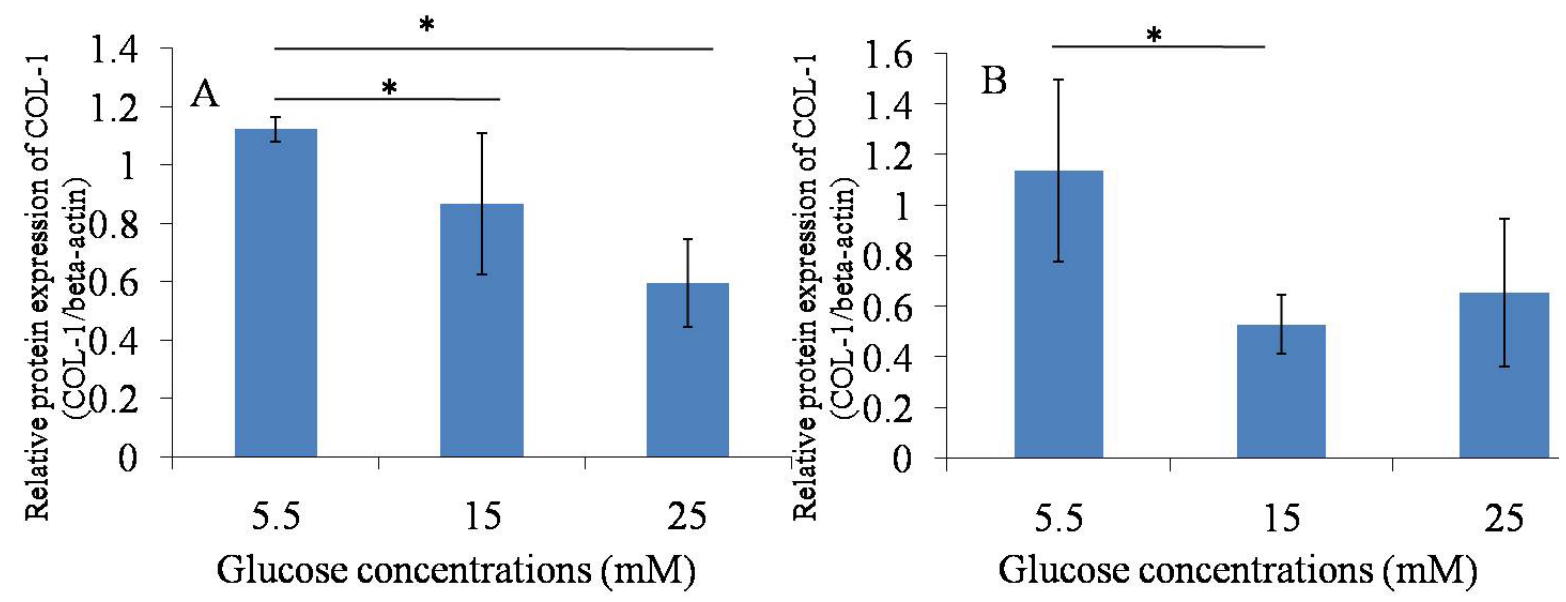

Figure 7: Western blotting ---- Col-1. A. 24h after glucose induction; B. 48h after glucose induction; The protein expression of Col-1 was decreased after the high glucose treatment $(15 \mathrm{mM}$ and $25 \mathrm{mM})$ for 24 hours and 48 hours compared with that in $5.5 \mathrm{mM}$ glucose group. $* P \leq 0.05$.

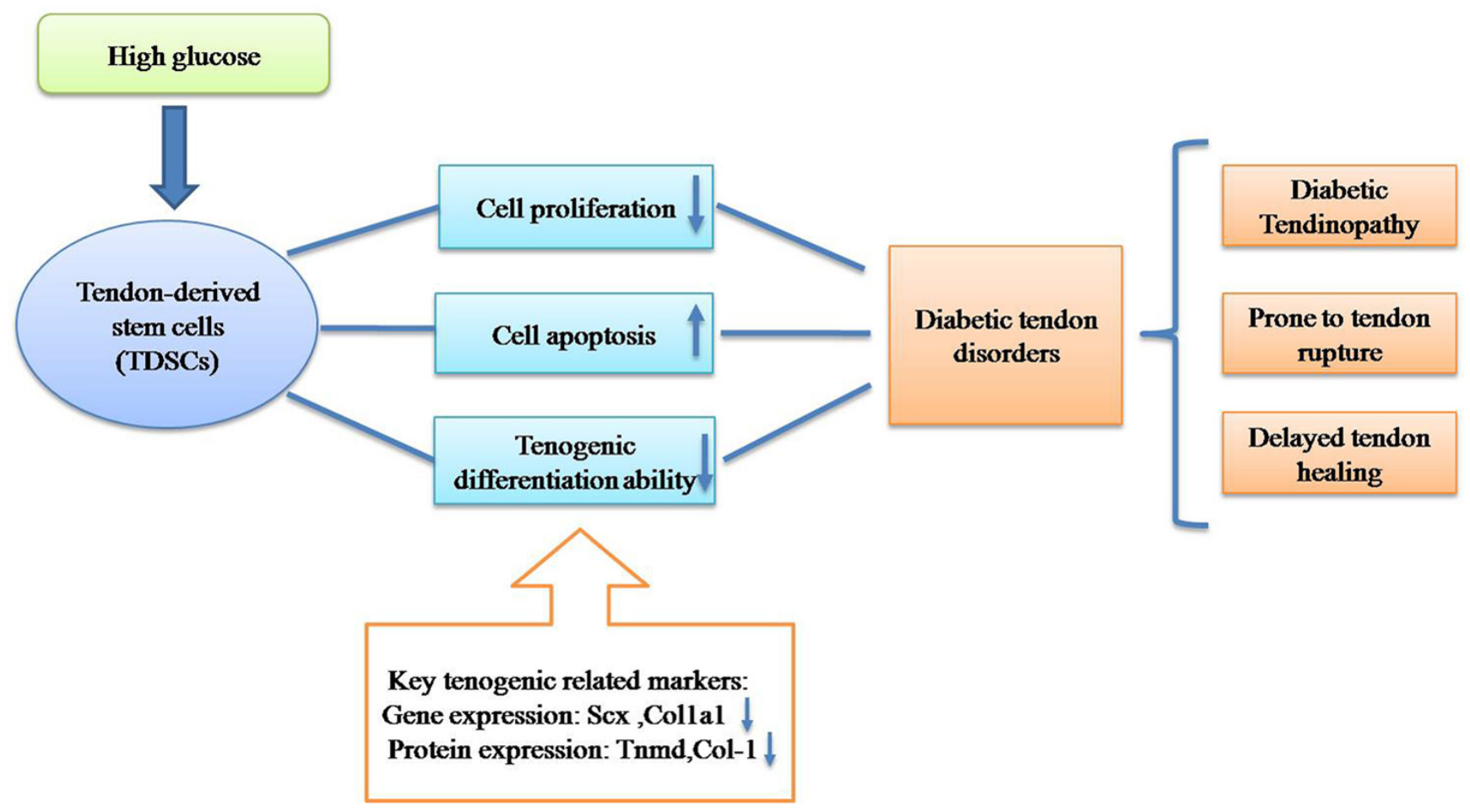

Figure 8: Hypothetical model of pathogenesis of diabetic tendon disorders. 
differentiation, whereas Mkx plays a vital role in tendon maturation [34]. In this study, we chose Scx instead of Mkx to see the ability of tendon differentiation. Tenascin $\mathrm{C}$ (TN-C) is expressed in the extracellular matrix of different cell types during development, disease or injury. Expression of TN-C varies from childhood to adulthood. TN-C is highly expressed during embryogenesis or in developing tendons, bone and cartilage while in developed organs, expression is absent or in a trace expression [35]. So, we believe that TN-C is a more appropriate maker for the stemness of TDSCs. Therefore, in this study, we investigated the mRNA expression of Scx and Colla1, the protein expression of Tnmd and collagen I in order to compare tendon-related markers expression of TDSCs under different glucose concentrations in vitro. Our results showed that high glucose concentrations $(15 \mathrm{mM}$ and $25 \mathrm{mM}$ ) suppressed the gene expression of tenodon-related makers (Scx and Colla1) and the protein expression of tendon-related markers (Tnmd and Col-1) after $24 \mathrm{~h}$ and $48 \mathrm{~h}$ culture. Because of this, the suppression of tendonrelated markers of TDSCs may suggest that tenogenic differentiation ability of TDSCs is impaired in diabetic tendons. Exposure to high glucose environment leads to impaired tendon healing and making the tendon vulnerable to rupture in the initial stage. The findings are consistent with changes, such as disordered collagen fibers, reduced biomechanical properties, impaired tendon healing ability and decreased proteoglycan levels observed in injured diabetic tendons $[17,19,36]$.

Actually, the molecular mechanisms of high glucose affecting stem cell proliferation, apoptosis and differentiation still remains unclear. In this study, our findings suggested that high glucose altered the fate of TDSCs in vitro. Snedeker JG illustrated that advanced glycation end-products (AGEs) pathologically disrupted tendon homeostasis and damaged tendon repair process [37]. The uncontrolled reactions between glucose and the extracellular matrix, excessive accumulation of AGEs, the altered inflammatory responses, neo-vascularization and dysregulation of TDSCs differentiation might account for mechanisms of the effects of high glucose on TDSCs. The underlying molecular mechanisms need further investigated.

There are also some limitations in this study. This experiment was an in vitro study, and incubation of TDSCs with high concentrations of glucose in vitro may not mimic the in vivo conditions of hyperglycemia in the patients. Therefore, further animal studies should be done to certify the effects of high glucose on TDSCs in vivo. Meanwhile, whether the glucose concentrations used in this study are the most appropriate need to be further verified. Moreover, the expression of tendon-related markers were showed a downward trend in this study. With the extension of incubation time in high glucose environment, whether TDSCs are activated again after injury and then self-healing need to do further research.

\section{CONCLUSIONS}

High glucose could inhibit proliferation, induce cell apoptosis and suppress the tendon-related markers expression of TDSCs in vitro. These results may partly explain the pathological and molecular mechanisms of the pathogenesis of diabetic tendon disorders.

\section{MATERIALS AND METHODS}

\section{Isolation and culture of rat TDSCs}

All experiments were approved by the Animal Research Ethics Committee of Southeast University. The procedures for the isolation of TDSCs from rat patellar tendon have been well-established [10]. Briefly, the midsubstance of patellar tendons were excised from rats overdosed with $2.5 \%$ sodium phenobarbital. Care was taken that only the mid-substance of the patellar tendon tissue, but not the tissue at the bone-tendon junction, was collected. Peritendinous connective tissue was carefully removed and the samples were stored in sterile phosphatebuffered saline (PBS). The tissues were minced, digested with type I collagenase ( $3 \mathrm{mg} / \mathrm{mL}$; Sigma-Aldrich), and passed through a $70 \mu \mathrm{m}$ cell strainer (Becton Dickinson, Franklin Lakes, NJ) to yield a single-cell suspension. The released cells were washed in PBS and resuspended in a complete culture medium [Dulbecco's Modified Eagle Medium (DMEM, low glucose formulation, glucose concentration: $5.5 \mathrm{mM}$ ), $10 \%$ fetal bovine serum, 100 $\mathrm{U} / \mathrm{mL}$ penicillin, $100 \mathrm{mg} / \mathrm{mL}$ streptomycin] (all from Invitrogen Corporation, Carlsbad, CA). The isolated nucleated cells were plated at an optimal low cell density (50 nucleated cells $/ \mathrm{cm}^{2}$ ) for the isolation of stem cells and cultured at $37^{\circ} \mathrm{C}, 5 \% \mathrm{CO}_{2}$ to form colonies. At day 2 , the cells were washed with phosphate buffered saline (PBS) to remove the nonadherent cells. At day 7, they were trypsinized and mixed together as passage0 (P0). Cells from P2 to P5 were used for all experiments. Medium was changed every 3 days. The clonogenicity and multi-lineage differentiation potential of these cells were confirmed before being used for the experiments in this study using standard assays as described previously [10]. We added D-Glucose (from Sigma-Aldrich, USA) with different weight to DMEM in order to make different concentrations of glucose in the cell culture medium.

\section{MTT (3- [4,5-Dimethylthiazol-2-yl]-2,5-diphenyltetrazolium bromide; Thiazolyl blue) assay}

The MTT assay was used to measure cell survival and proliferation. TDSCs were plated into 96-well culture plates at an optimal density of $3 \times 10^{3}$ cells/well in 200 $\mu \mathrm{L}$ complete culture medium. After 24 hours culture, the 
Table 1: Primer sequences and condition for $q R T-P C R$.

\begin{tabular}{|l|l|c|c|c|}
\hline Gene & Primer nucleotide sequence & $\begin{array}{l}\text { Product } \\
\text { size (bp) }\end{array}$ & $\begin{array}{l}\text { Annealing } \\
\text { temperature ( }{ }^{\circ} \text { C) }\end{array}$ & Accession no. \\
\hline$\beta$-actin & $\begin{array}{l}\text { 5'-ATCGTGGGCCGCCCTAGGCA-3' (forward) } \\
\text { 5'-TGGCCTTAGGGTTCAGAGGGG-3' (reverse) }\end{array}$ & 243 & 52 & NM_031144 \\
\hline Scleraxis & $\begin{array}{l}\text { 5'-AACACGGCCTTCACTGCGCTG-3' (forward) } \\
\text { 5'-CAGTAGCACGTTGCCCAGGTG-3' (reverse) }\end{array}$ & 102 & 58 & NM_001130508.1 \\
\hline Col1a1 & $\begin{array}{l}\text { 5'-CATCGGTGGTACTAAC-3'(forward) } \\
\text { 5'-CTGGATCATATTGCACA-3'(reverse) }\end{array}$ & 238 & & 55 \\
\hline
\end{tabular}

complete culture medium was aspirated and discarded from each well, then the cells were treated with medium containing different concentrations of glucose $(5.5 \mathrm{mM}$, $15 \mathrm{mM}$ and $25 \mathrm{mM}$ ). The cells were observed under a microscope and then the MTT assay was performed at day1, day3 and day5 after high glucose culture. DMEM, containing $5 \mathrm{mg} / \mathrm{mL}$ MTT (Sigma-Aldrich, USA), was added to each well and the plate was incubated at $37^{\circ} \mathrm{C}$ for 4 hours. Then, the MTT solution was removed and $150 \mu \mathrm{L}$ of dimethyl sulfoxide [DMSO (Sigma-Aldrich, USA)] was added to each well. After the crystals were dissolved by mixing with micro-pipette, the colorless DMSO turned purple. Subsequently, the absorbance of each well was immediately measured with an enzymelinked immunosorbant assay reader (model: $\mathrm{mk} 3$; Thermo Scientific, USA) at $570 \mathrm{~nm}$. These experiments were performed in triplicate.

\section{Apoptosis assay}

A propidium iodide (PI) and annexin V-FITC-flow cytometry assay (BD Pharmingen) was used to detect the apoptosis rate in the cells after the induction of different glucose concentrations. Briefly, $5 \times 10^{4}$ cells per well were cultured in 6-well plates in the complete culture medium for 24 hours. Then, the complete culture medium was aspirated and discarded from each well, cells were treated with medium containing different concentrations of glucose $(5.5 \mathrm{mM}, 15 \mathrm{mM}$ and $25 \mathrm{mM}$ ) for 24 hours and 48 hours. Adherent cells were detached with $0.25 \%$ trypsin without EDTA in $1 \times$ PBS. Cells were harvested in PBS and centrifuged at $2000 \mathrm{rpm}$ for 5 minutes. Then the cells were washed in PBS, re-suspended in binding buffer (BD Pharmingen), and stained with FITC-conjugated annexin $\mathrm{V}$ and propidium iodide (Pharmingen, Becton Dickinson Co., San Diego, CA, USA). After staining, the cells were incubated for 15 minutes in the dark at room temperature. Cells were analysed by flow cytometry (FACS Calibar; Becton-Dickinson) using Cell Quest software.

\section{Quantitative real-time reverse transcription- polymerase chain reaction (qRT-PCR)}

qRT-PCR was performed as previously described [38]. After the culture of different concentrations of glucose medium $(5.5 \mathrm{mM}, 15 \mathrm{mM}$ and $25 \mathrm{mM})$ for $24 \mathrm{~h}$ and $48 \mathrm{~h}$, cells were harvested and homogenized for RNA extraction with the Rneasy mini kit (Qiagen $\mathrm{GmbH}$, Hilden, Germany). The mRNA was reverse transcribed to cDNA by the First-Strand cDNA kit (Promega, Madison, WI). $1 \mu \mathrm{L}$ of total cDNA of each sample was amplified in the final volume of $20 \mu \mathrm{L}$ of reaction mixture containing Power SYBR Green PCR Master Mix (Invitrogen Corporation, Carlsbad, CA) and specific primers for Scx and Col1a1 using the ABI StepOne Plus system (all from Applied Biosystems, CA, USA) (Table 1). Cycling conditions were denaturation at $95^{\circ} \mathrm{C}$ for $10 \mathrm{~min}, 45$ cycles at $95^{\circ} \mathrm{C}$ for $20 \mathrm{~s}$, optimal annealing temperature (Table 1) for $20 \mathrm{~s}, 72^{\circ} \mathrm{C}$ for $30 \mathrm{~s}$, and finally at $60^{\circ} \mathrm{C}-95^{\circ} \mathrm{C}$ with a heating rate of $0.1{ }^{\circ} \mathrm{C} / \mathrm{s}$. The expression of the target gene was normalized to that of the $\beta$-actin gene. Relative gene expression was calculated using the $2^{-\mathrm{ACT}}$ formula.

\section{Western blotting}

After the culture of different concentrations of glucose medium $(5.5 \mathrm{mM}, 15 \mathrm{mM}$ and $25 \mathrm{mM})$ for $24 \mathrm{~h}$ and $48 \mathrm{~h}$, the cells were lysed, centrifuged, and the supernatant was then collected for measurement of protein concentration by BCA protein assay (Thermo Scientific, Rockford, IL, USA ). $50 \mu \mathrm{g}$ of protein was denatured, fractionated by electrophoresis on $10 \%$ (Tnmd) or $8 \%(\mathrm{Col}-1)(\mathrm{w} / \mathrm{v})$ SDS-PAGE and electrophoretically transferred to a PVDF membrane (Millipore, Billerica, MA). The blots were blocked with $5 \%(\mathrm{w} / \mathrm{v})$ nonfat dry milk in TBST solution [25 mM Trizma base $(3.025 \mathrm{~g}), 125$ $\mathrm{mM} \mathrm{NaCl}(7.3 \mathrm{~g})$ and $1 \mathrm{ml}$ Tween-20, $\mathrm{pH}$ 7.6], incubated with primary antibody against Tnmd (1:1000), Col-1 (1:1000) (all from Abcam, Cambridge, UK), followed by horseradish peroxidase-conjugated secondary antibody 
(1:3000; Santa Cruz Biotechnology, Santa Cruz , CA , USA). Immunoreactive bands were detected by ECL reagents (Pierce Biotechnology Inc., Rockford, IL). The membranes were stripped with Restore Western blot stripping buffer (Pierce Biotechnology Inc., Rockford, IL) and reprobed with $\beta$-actin antibody (1:3000) (R\&D Systems, Inc., Minneapolis, MN) as a house-keeping control. Semiquantitative image analyses of protein expression were performed using the Image J Software (Wayne Rasband, National Institutes of Health, USA), and the mean expression level of the target protein relative to $\beta$-actin was presented.

\section{Data analysis}

All data are presented in mean \pm standard deviation (SD). For statistical analysis of the data in this assay, comparison of more than two groups was done using Kruskal-Wallis test followed by post hoc comparison with control group using Mann-Whitney U-test. Differences between groups were measured by the Mann-Whitney U-test. All the data analysis was done using SPSS analysis software (SPSS, Inc., Chicago, IL; version 18.0). P $\leq 0.05$ was regarded as statistically significant difference.

\section{Abbreviations}

TDSCs: tendon-derived stem cells; Tnmd: tenomodulin; Scx: scleraxis; Col-1: collagen I; colla1: collagen I alpha 1 chain; DMEM: Dulbecco's Modified Eagle Medium.

\section{ACKNOWLEDGMENTS}

This work was supported by National Natural Science Foundation of China (81572187); National Natural Science Foundation of China for Young Scholars (81201422, 81301565); China Postdoctoral Science Foundation (2012M520983); Special Projects of China Postdoctoral Science Foundation (2014T70461); National Student Innovation Training Program of China (1210286090); Natural Science Foundation of Jiangsu Province for Young Scholars (BK2012334, BK20150641); "Summit of the Six Top Talents" Program of Jiangsu Province (Grant No: 2013-WSW-054); Innovative Foundation of Southeast University (3290002401); Wuxi City Science and Technology Development/Medical and Public Health Technology Research and Development Project Funding (CSE31N1517).

\section{CONFLICTS OF INTEREST}

The authors declare that there is no conflict of interest regarding the publication of this manuscript.

\section{Authors' contributions}

Y.-C. L., Y.-J. L., Y.-F. R.and G.-J. T. were the main researchers for this study, they planned the study, wrote the protocol, collected the data, performed the statistical analysis and contributed to writing this manuscript. G.C. D. and L. S. did the technical work. H.-L. X., M. N. and S. Z. helped with data collection, study design and coordinated the study. H. C., C. W., and G. L. participated in study design and helped to revise the manuscript critically. All authors read and approved the final manuscript.

\section{REFERENCES}

1. Cagliero E, Apruzzese W, Perlmutter GS, Nathan DM. Musculoskeletal disorders of the hand and shoulder in patients with diabetes mellitus. Am J Med. 2002; 112: 48790.

2. Rosenbloom AL, Silverstein JH. Connective tissue and joint disease in diabetes mellitus. Endocrinol Metab Clin North Am. 1996; 25: 473-83.

3. Sukenik S, Weitzman S, Buskila D, Eyal A, Gross J, Horowitz J. Limited joint mobility and other rheumatological manifestations in diabetic patients. Diabete Metab. 1987; 13: 187-92.

4. Bedi A, Fox AJ, Harris PE, Deng XH, Ying L, Warren RF, Rodeo SA. Diabetes mellitus impairs tendon-bone healing after rotator cuff repair. J Shoulder Elbow Surg. 2010; 19: 978-88. doi: 10.1016/j.jse.2009.11.045.

5. Ranger TA, Wong AM, Cook JL, Gaida JE. Is there an association between tendinopathy and diabetes mellitus? A systematic review with meta-analysis. Br J Sports Med. 2015. doi: 10.1136/bjsports-2015-094735.

6. Maffulli N, Longo UG, Maffulli GD, Khanna A, Denaro V. Achilles tendon ruptures in diabetic patients. Arch Orthop Trauma Surg. 2011; 131: 33-8. doi: 10.1007/s00402-0101097-0.

7. Fox AJ, Bedi A, Deng XH, Ying L, Harris PE, Warren RF, Rodeo SA. Diabetes mellitus alters the mechanical properties of the native tendon in an experimental rat model. J Orthop Res. 2011; 29: 880-5. doi: 10.1002/jor.21327.

8. Bi Y, Ehirchiou D, Kilts TM, Inkson CA, Embree MC, Sonoyama W, Li L, Leet AI, Seo BM, Zhang L, Shi S, Young MF. Identification of tendon stem/progenitor cells and the role of the extracellular matrix in their niche. Nat Med. 2007; 13: 1219-27. doi: 10.1038/nm1630.

9. Zhang J, Pan T, Liu Y, Wang JH. Mouse treadmill running enhances tendons by expanding the pool of tendon stem cells (TSCs) and TSC-related cellular production of collagen. J Orthop Res. 2010; 28: 1178-83. doi: 10.1002/ jor.21123.

10. Rui YF, Lui PP, Li G, Fu SC, Lee YW, Chan KM. Isolation and characterization of multipotent rat tendon-derived stem 
cells. Tissue Eng Part A. 2010; 16: 1549-58. doi: 10.1089/ ten.TEA.2009.0529.

11. Zhang J, Wang JH. Characterization of differential properties of rabbit tendon stem cells and tenocytes. BMC Musculoskelet Disord. 2010; 11: 10. doi: 10.1186/14712474-11-10.

12. Ni M, Lui PP, Rui YF, Lee YW, Tan Q, Wong YM, Kong SK, Lau PM, Li G, Chan KM. Tendon-derived stem cells (TDSCs) promote tendon repair in a rat patellar tendon window defect model. J Orthop Res. 2012; 30: 613-9. doi: 10.1002/jor.21559.

13. Lui PP, Rui YF, Ni M, Chan KM. Tenogenic differentiation of stem cells for tendon repair-what is the current evidence? J Tissue Eng Regen Med. 2011; 5: e144-63. doi: 10.1002/ term.424.

14. Zhang X, Lin YC, Rui YF, Xu HL, Chen H, Wang C, Teng GJ. Therapeutic Roles of Tendon Stem/Progenitor Cells in Tendinopathy. Stem Cells Int. 2016; 2016: 4076578. doi: 10.1155/2016/4076578.

15. Rui YF, Lui PP, Chan LS, Chan KM, Fu SC, Li G. Does erroneous differentiation of tendon-derived stem cells contribute to the pathogenesis of calcifying tendinopathy? Chin Med J (Engl). 2011; 124: 606-10.

16. Rui YF, Lui PP, Wong YM, Tan Q, Chan KM. Altered fate of tendon-derived stem cells isolated from a failed tendonhealing animal model of tendinopathy. Stem Cells Dev. 2013; 22: 1076-85. doi: 10.1089/scd.2012.0555.

17. Shi L, Rui YF, Li G, Wang C. Alterations of tendons in diabetes mellitus: what are the current findings? Int Orthop. 2015; 39: 1465-73. doi: 10.1007/s00264-015-2775-x.

18. Longo UG, Franceschi F, Ruzzini L, Spiezia F, Maffulli N, Denaro V. Higher fasting plasma glucose levels within the normoglycaemic range and rotator cuff tears. Br J Sports Med. 2009; 43: 284-7. doi: 10.1136/bjsm.2008.049320.

19. Burner T, Gohr C, Mitton-Fitzgerald E, Rosenthal AK. Hyperglycemia reduces proteoglycan levels in tendons. Connect Tissue Res. 2012; 53: 535-41. doi: 10.3109/03008207.2012.710670.

20. Poulsen RC, Knowles HJ, Carr AJ, Hulley PA. Cell differentiation versus cell death: extracellular glucose is a key determinant of cell fate following oxidative stress exposure. Cell Death Dis. 2014; 5: e1074. doi: 10.1038/ cddis.2014.52.

21. Tsai WC, Liang FC, Cheng JW, Lin LP, Chang SC, Chen $\mathrm{HH}$, Pang JH. High glucose concentration up-regulates the expression of matrix metalloproteinase- 9 and -13 in tendon cells. BMC Musculoskelet Disord. 2013; 14: 255. doi: 10.1186/1471-2474-14-255.

22. Thomas K, Kiwit M, Kerner W. Glucose concentration in human subcutaneous adipose tissue: comparison between forearm and abdomen. Exp Clin Endocrinol Diabetes. 1998; 106: 465-9. doi: 10.1055/s-0029-1212017.

23. Rui YF, Lui PP, Rolf CG, Wong YM, Lee YW, Chan KM. Expression of chondro-osteogenic BMPs in clinical samples of patellar tendinopathy. Knee Surg Sports Traumatol Arthrosc. 2012; 20: 1409-17. doi: 10.1007/s00167-0111685-8.

24. Abate M, Silbernagel KG, Siljeholm C, Di Iorio A, De Amicis D, Salini V, Werner S, Paganelli R. Pathogenesis of tendinopathies: inflammation or degeneration? Arthritis Res Ther. 2009; 11: 235. doi: 10.1186/ar2723.

25. de Oliveira RR, Martins CS, Rocha YR, Braga AB, Mattos RM, Hecht F, Brito GA, Nasciutti LE. Experimental diabetes induces structural, inflammatory and vascular changes of Achilles tendons. PLoS One. 2013; 8: e74942. doi: 10.1371/journal.pone.0074942.

26. Cao C, Zhang H, Gong L, He Y, Zhang N. High glucose conditions suppress the function of bone marrow-derived endothelial progenitor cells via inhibition of the eNOScaveolin-1 complex. Mol Med Rep. 2012; 5: 341-6. doi: 10.3892/mmr.2011.644.

27. Cramer C, Freisinger E, Jones RK, Slakey DP, Dupin CL, Newsome ER, Alt EU, Izadpanah R. Persistent high glucose concentrations alter the regenerative potential of mesenchymal stem cells. Stem Cells Dev. 2010; 19: 187584. doi: 10.1089/scd.2010.0009.

28. Kim HS, Park JW, Yeo SI, Choi BJ, Suh JY. Effects of high glucose on cellular activity of periodontal ligament cells in vitro. Diabetes Res Clin Pract. 2006; 74: 41-7. doi: 10.1016/j.diabres.2006.03.034.

29. Tchounwou CK, Yedjou CG, Farah I, Tchounwou PB. D-Glucose-Induced Cytotoxic, Genotoxic, and Apoptotic Effects on Human Breast Adenocarcinoma (MCF-7) Cells. J Cancer Sci Ther. 2014; 6: 156-60. doi: 10.4172/19485956.1000265.

30. Chen J, Guo Y, Cheng W, Chen R, Liu T, Chen Z, Tan S. High glucose induces apoptosis and suppresses proliferation of adult rat neural stem cells following in vitro ischemia. BMC Neurosci. 2013; 14: 24. doi: 10.1186/1471-2202-1424.

31. Espira L, Lamoureux L, Jones SC, Gerard RD, Dixon IM, Czubryt MP. The basic helix-loop-helix transcription factor scleraxis regulates fibroblast collagen synthesis. J Mol Cell Cardiol. 2009; 47: 188-95. doi: 10.1016/j. yjmcc.2009.03.024.

32. Shukunami C, Takimoto A, Oro M, Hiraki Y. Scleraxis positively regulates the expression of tenomodulin, a differentiation marker of tenocytes. Dev Biol. 2006; 298: 234-47. doi: 10.1016/j.ydbio.2006.06.036.

33. Zhang J, Keenan C, Wang JH. The effects of dexamethasone on human patellar tendon stem cells: implications for dexamethasone treatment of tendon injury. J Orthop Res. 2013; 31: 105-10. doi: 10.1002/jor.22193.

34. Onizuka $N$, Ito $Y$, Inagawa $M$, Nakahara $H$, Takada $S$, Lotz M, Toyama Y, Asahara H. The Mohawk homeobox transcription factor regulates the differentiation of tendons and volar plates. J Orthop Sci. 2014; 19: 172-80. doi: 10.1007/s00776-013-0485-z. 
35. Chiquet-Ehrismann R. Tenascins. Int J Biochem Cell Biol. 2004; 36: 986-90. doi: 10.1016/j.biocel.2003.12.002.

36. Ahmed AS, Schizas N, Li J, Ahmed M, Ostenson CG, Salo P, Hewitt C, Hart DA, Ackermann PW. Type 2 diabetes impairs tendon repair after injury in a rat model. J Appl Physiol (1985). 2012; 113: 1784-91. doi: 10.1152/ japplphysiol.00767.2012.
37. Snedeker JG. How High Glucose Levels Affect Tendon Homeostasis. Adv Exp Med Biol. 2016; 920: 191-8. doi: 10.1007/978-3-319-33943-6_18.

38. Tan Q, Lui PP, Rui YF. Effect of in vitro passaging on the stem cell-related properties of tendon-derived stem cellsimplications in tissue engineering. Stem Cells Dev. 2012; 21: 790-800. doi: 10.1089/scd.2011.0160. 